\title{
Faktor Yang Berhubungan Dengan Keluhan Nyeri Punggung Bawah Pada Pengrajin Gerabah Di Lingkungan Sandi Kelurahan Pallantikang Kecamatan Pattallassang Kabupaten Takalar Syarlina ${ }^{1}$ dan Hidayat ${ }^{2}$ \\ 1.2 Jurusan Kesehatan Lingkungan Politeknik Kesehatan Kemenkes Makassar
} (Syarlina96@gmail.com)

\begin{abstract}
Lower Back Pain (NPB) is a type of disease that many complained of by craftsmen. This is caused by the repetition done over and over for a long time. Types of complaints commonly experienced by artisans among the hot feeling, stiff, pain punctured on the lower back. This research is to know the factors related to the occurrence of low back pain in the pottery craftsmen in the password environment. This research is researching an analytic observation with a cross-sectional study design, the number of samples is 67 people and with the sampling method using simple random sampling and data analysis tested with doing a statistical test that is chi-square. The result of the research shows that from the four variables studied, there is one variable that has no significant correlation between the length of work, the working period and the work attitude can not be tested because all the craftsmen are following the standard and one variable that has a significant relationship that is age. It is expected for the craftsmen to often stretch the muscles when feeling cramps or pain in the body and do regular exercise and eat foods that contain many nutrients.
\end{abstract}

Keywords: Back Pain, Craftsman, Age, Duration Of Work, Work Period, Work Attitude.

\section{ABSTRAK}

Nyeri Punggung Bawah (NPB) merupakan jenis penyakit yang banyak dikeluhkan oleh pengrajin. Hal ini diakibatkan oleh gerakan yang dilakukan berulang-ulang dalam jangka waktu yang lama. Jenis keluhan yang biasa dirasakan oleh pengrajin diantara adalah rasa panas, kaku, nyeri tertusuk-tusuk pada bagian punggung bawah. Penelitian ini untuk mengetahui faktor yang berhubungan dengan kejadian nyeri punggung bawah pada pengrajin gerabah di lingkungan sandi.Penelitian ini merupakan penelitian observasion alanalitik dengan desain cross sectional study, jumlah sampel sebanyak 67 orang dan dengan metode penarikan sampel menggunakan simple random sampling dan analisis data diuji dengan melakukan uji statistic yaitu chi-square. Hasil penelitian diperoleh bahwa dari empat variabel yang diteliti terdapat satu variabel yang tidak memiliki hubungan bermakna yaitu lama kerja, untuk masa kerja dan sikap kerja tidak dapat diuji analisis karena semua pengrajin sesuai dengan standar dan satu variabel yang memiliki hubungan bermakna yaitu umur. Diharapkan bagi para pengrajin untuk sering melakukan peregangan otot ketika merasakan kram atau sakit pada bagian tubuh serta melakukan olahraga yang teratur dan makan makanan yang banyak mengandung gizi.

Kata Kunci: Nyeri Punggung, Pengerajin, Umur, Lama Kerja, Masa Kerja, Sikap Kerja.

\section{PENDAHULUAN}

Industri kerajinan di Indonesia semakin berkembang. Kementerian Perindustrian Republik Indonesia (2014) menyatakan bahwa pertumbuhan industri kerajinan Indonesia mencapai angka tujuh persen. Pertumbuhan tersebut dapat dibuktikan dari meningkatnya permintaan produk kerajinan Indonesia di Asia.Yogyakarta, Bandung, Jakarta, Solo, dan Bali merupakan sejumlah daerah dimana sektor industri kerajinannya berkembang. Sikap kerja yang statis dapat menimbulkan masalah kesehatan pada pengrajin. Pekerja yang melakukan suatu pekerjaan dengan posisi duduk dalam jangka waktu yang lama pada kursi yang kurang ergonomis juga dapat menyebabkan masalah kesehatan. Nyeri punggung merupakan salah satu masalah yang dihadapi oleh pengrajin akibat posisi duduk saat bekerja (Laura dkk, 2005 dalam Gempur, 2013) menemukan bahwa nyeri punggung bawah disebabkan oleh posisi duduk yang tidak ergonomis.

Pada studi kolaborasi tentang nyeri yang dilakukan oleh WHO (2013) didapatkan hasil bahwa $33 \%$ penduduk di negara berkembang mengalami nyeri persisten. Nyeri ini pada akhirnya akan berkaitan dengan kondisi depresi, sehingga dapat mengganggu kualitas hidup dan menurunkan level aktivitas pekerja. Pernyataan oleh WHO ini didukung penelitian yang dilakukan oleh Mortimer et al (2007) dan The UMHS Clinical Care Guidelines Commite (2007) yang memberikan gambaran distribusi anatomi dari neuralgia. $56 \%$ terjadi di regio thorax, $13 \%$ dibagian wajah, $13 \%$ di regio lumbai, dan $11 \%$ di regio survikal.

Nyeri punggung merupakan salah satu masalah yang dihadapi oleh banyak negara. Hoy (2012) menemukan bahwa angka prevalensi nyeri pungggung bawah di seluruh dunia sebanyak 18,3\%. Taylor (2011) menganalisa intensitas nyeri punggung kronis pada 1.363 pasien didapatkan data bahwa $(28,3 \%)$ menderita nyeri ringan, $(52,8 \%)$ nyeri sedang dan $(18,0 \%)$ nyeri berat. Data Departemen Kesehatan (dalam Heriyanto, 2004) menunjukan petani kelapa sawit di Riau $(31,6 \%)$, pengrajin wayang kulit di Yogyakarta (21\%), pengrajin onix di Jawa Barat (18\%), penambang emas di Kalimantan Barat (16\%), perajin sepatu di Bogor $(14,9 \%)$ dan $(8 \%)$ pengrajin kuningan di Jawa Tengah, perajin batu bata di Lampung $(76,7 \%)$ dan nelayan di DKI Jakarta $(41,6 \%)$ mengeluh 
nyeri punggung. Data tersebut melibatkan 800 orang dari delapan sektor informal di Indonesia.

\section{BAHAN DAN METODE}

\section{Lokasi Penelitian:}

Penelitian ini berlokasi di di Lingkungan Sandi yang terletak $\mathrm{Di}$ Kelurahan Pallantikang Kecamatan Pattallassang Kabupaten Takalar.

\section{Desain dan Variabel Penelitian}

Jenis penelitian ini adalah observasional analitik yaitu, penelitian diarahkan untuk menjelaskan suatu keadaan atau situasi. Penelitian ini menggunakan pendekatan analitik dengan rancangan penelitian secara cross sectional.

Adapun variabel penelitian pada penelitian ini terdiri dari 3 variabel. Yaitu variabel bebas yang terdiri dari umur, lama kerja, masa kerja, dan sikap kerja. Variabel terikat yaitu nyeri punggung bawah dan variabel pengganggu yaitu tempat duduk.

\section{Populasi dan Sampel}

Populasi dalam penelitian ini adalah semua pengrajin gerabah yang berjumlah 80 orang di Lingkungan Sandi Kelurahan Pallantikang Kecamatan Pattallassang Kabupaten Takalar.

Sampel dalam penelitian ini adalah pengrajin gerabah di Lingkungan Sandi Kelurahan Pallantikang Kecamatan Pattallassang Kabupaten Takalar yang berjumlah 67 responden. Dalam hal ini peneliti menggunakan besarnya sampel dengan menggunakan rumus dari metode Rumus Slovin

4. Pengumpulan data

Sumber data terdiri dari 2 yaitu Data primer diperoleh dari hasil observasi langsung dan wawancara menggunakan lembar kuesioner dan data sekunder yang diperoleh dari sumber lain seperti, laporan pemerintah, buku, jurnal, dan karya tulis ilmiah.

5. Analisa Data (Jika memakai program statistic, tuliskan uji utama apa yang digunakan)

Analisis Univariat adalah untuk menjelaskan atau mendeskripsikan karakteristik setiap variabel penelitian. Dalam analisis ini hanya mmenghasilkan distribusi frekuensi dan presentase tiap variabel. Distibusi frekuensi dan presentase tunggal pada karakteristik umum responden (umur, lama kerja, masa kerja, sikap kerja).
Analisis bivariat adalah untuk mengetahui adanya hubungan antara variabel independen dan dependen. Analisis ini menggunakan uji statistik dengan program Statistic Product and Service Solutions (SPSS) berupa Uji chi-square.

\section{HASIL}

1. Hubungan antara umur dengan keluhan nyeri punggung bawah.

Tabel 1

Hubungan Umur Dengan Keluhan Nyeri Punggung Bawah Pada Pengrajin Gerabah Di Lingkungan Sandi Tahun 2018

\begin{tabular}{|c|c|c|c|c|c|c|c|c|c|}
\hline \multirow{3}{*}{$\underset{r}{\text { Umu }}$} & \multicolumn{6}{|c|}{ Keluhan } & \multirow{3}{*}{$\begin{array}{c}\text { Tota } \\
\text { I }\end{array}$} & \multirow{3}{*}{$\%$} & \multirow{3}{*}{$p$} \\
\hline & \multicolumn{2}{|c|}{ Selalu } & \multicolumn{2}{|c|}{ Jarang } & \multicolumn{2}{|c|}{$\begin{array}{c}\text { Tidak } \\
\text { Perna } \\
\text { h }\end{array}$} & & & \\
\hline & $n$ & $\%$ & $\mathrm{~N}$ & $\%$ & $\mathrm{n}$ & $\%$ & & & \\
\hline $\begin{array}{c}<40 \\
\text { tahu } \\
n \\
\end{array}$ & 7 & $\begin{array}{l}5 \\
0\end{array}$ & 7 & $\begin{array}{l}5 \\
0\end{array}$ & 0 & 0 & 14 & $\begin{array}{c}10 \\
0\end{array}$ & \\
\hline $\begin{array}{c}\geq 40 \\
\text { tahu } \\
n\end{array}$ & $\begin{array}{l}4 \\
1\end{array}$ & $\begin{array}{l}7 \\
7\end{array}$ & $\begin{array}{l}1 \\
2\end{array}$ & $\begin{array}{l}2 \\
3\end{array}$ & 0 & 0 & 53 & $\begin{array}{c}10 \\
0\end{array}$ & $\begin{array}{c}0,02 \\
8\end{array}$ \\
\hline Total & $\begin{array}{l}4 \\
8\end{array}$ & $\begin{array}{l}7 \\
2\end{array}$ & $\begin{array}{l}1 \\
9\end{array}$ & $\begin{array}{l}2 \\
8\end{array}$ & 0 & 0 & 67 & $\begin{array}{c}10 \\
0\end{array}$ & \\
\hline
\end{tabular}

Sumber : Data Primer, 2018

2. Hubungan antara lama kerja dengan keluhan nyeri punggung bawah. Tabel 2

Hubungan Lama Kerja Dengan Keluhan Nyeri Punggung Bawah Pada Pengrajin Gerabah Di Lingkungan Sandi Tahun 2018

\begin{tabular}{|c|c|c|c|c|c|c|c|c|c|}
\hline \multirow{3}{*}{$\begin{array}{l}\text { Lam } \\
\text { a } \\
\text { Kerja }\end{array}$} & \multicolumn{6}{|c|}{ Keluhan } & \multirow{3}{*}{$\begin{array}{l}\text { Tota } \\
\text { I }\end{array}$} & \multirow{3}{*}{$\%$} & \multirow{3}{*}{$\mathbf{p}$} \\
\hline & \multicolumn{2}{|c|}{ Selalu } & \multicolumn{2}{|c|}{ Jarang } & \multicolumn{2}{|c|}{$\begin{array}{l}\text { Tidak } \\
\text { Perna } \\
\text { h }\end{array}$} & & & \\
\hline & $\mathrm{n}$ & $\%$ & $\mathrm{n}$ & $\%$ & $n$ & $\%$ & & & \\
\hline $\begin{array}{l}\leq 8 \\
\text { jam }\end{array}$ & $\begin{array}{l}4 \\
4\end{array}$ & $\begin{array}{l}6 \\
6\end{array}$ & $\begin{array}{l}1 \\
8\end{array}$ & $\begin{array}{l}2 \\
7\end{array}$ & 0 & 0 & 62 & 100 & \\
\hline $\begin{array}{l}>8 \\
\text { jam }\end{array}$ & 4 & $\begin{array}{l}8 \\
0\end{array}$ & 1 & $\begin{array}{l}2 \\
0\end{array}$ & 0 & 0 & 5 & 100 & $\begin{array}{l}0,66 \\
6\end{array}$ \\
\hline Total & $\begin{array}{l}4 \\
8\end{array}$ & $\begin{array}{l}7 \\
2\end{array}$ & $\begin{array}{l}1 \\
9\end{array}$ & $\begin{array}{l}2 \\
8\end{array}$ & 0 & 0 & 67 & 100 & \\
\hline
\end{tabular}

Sumber : Data Primer, 2018 


\section{Hubungan antara masa kerja dengan keluhan nyeri punggung bawah. Tabel 3}

Hubungan Masa Kerja Dengan Keluhan Nyeri Punggung Bawah Pada Pengrajin Gerabah Di Lingkungan Sandi Tahun 2018

\begin{tabular}{|c|c|c|c|c|c|c|c|c|}
\hline \multirow{3}{*}{$\begin{array}{l}\text { Masa } \\
\text { Kerja }\end{array}$} & \multicolumn{6}{|c|}{ Keluhan } & \multirow{3}{*}{ Total } & \multirow{3}{*}{$\%$} \\
\hline & \multicolumn{2}{|c|}{ Selalu } & \multicolumn{2}{|c|}{ Jarang } & \multicolumn{2}{|c|}{$\begin{array}{l}\text { Tidak } \\
\text { Pernah }\end{array}$} & & \\
\hline & $\mathrm{n}$ & $\%$ & $\mathrm{~N}$ & $\%$ & $\mathrm{~N}$ & $\%$ & & \\
\hline Lama & 48 & 72 & 19 & 28 & 0 & 0 & 67 & 100 \\
\hline Baru & 0 & 0 & 0 & 0 & 0 & 0 & 0 & 0 \\
\hline Total & 48 & 72 & 19 & 28 & 0 & 0 & 67 & 100 \\
\hline
\end{tabular}

4. Hubungan antara sikap kerja dengan keluhan nyeri punggung bawah. Tabel 4

Hubungan Sikap Kerja Dengan Keluhan Nyeri Punggung Bawah Pada Pengrajin Gerabah Di Lingkungan Sandi Tahun 2018

\begin{tabular}{|c|c|c|c|c|c|c|c|c|}
\hline \multirow{3}{*}{$\begin{array}{l}\text { Masa } \\
\text { Kerja }\end{array}$} & \multicolumn{6}{|c|}{ Keluhan } & \multirow{3}{*}{ Total } & \multirow{3}{*}{$\%$} \\
\hline & \multicolumn{2}{|c|}{ Selalu } & \multicolumn{2}{|c|}{ Jarang } & \multicolumn{2}{|c|}{$\begin{array}{l}\text { Tidak } \\
\text { Pernah }\end{array}$} & & \\
\hline & $\mathrm{n}$ & $\%$ & $\mathrm{~N}$ & $\%$ & $\mathrm{~N}$ & $\%$ & & \\
\hline Lama & 48 & 72 & 19 & 28 & 0 & 0 & 67 & 100 \\
\hline Baru & 0 & 0 & 0 & 0 & 0 & 0 & 0 & 0 \\
\hline Total & 48 & 72 & 19 & 28 & 0 & 0 & 67 & 100 \\
\hline
\end{tabular}

Sumber : Data Primer, 2018

\section{PEMBAHASAN}

1. Umur

Umur diartikan sebagai lama waktu hidup atau ada (sejak dilahirkan atau diadakan) (Hoetomo,2005).Distribusi responden berdasarkan umur memperlihatkan dari 67 pengrajin gerabah yang berumur tua ( $\geq 40$ tahun) sebanyak 53 orang $(79 \%)$ dan yang berumur muda $(<40$ tahun) 14 orang $(21 \%)$. Hasil tabulasi silang antara umur dengan keluhan nyeri punggung bawah pada pengrajin gerabah menunjukkan bahwa responden dengan keluhan nyeri punggung bawah lebih tinggi pada usia tua yaitu sebanyak 41 responden. Berdasarkan hasil uji statistik (tabel 5.7) diperoleh $p$ value $0,028(<0,05)$ hal ini menunjukkan bahwa ada hubungan antara umur pengrajin dengan keluhan nyeri punggung bawah.

Keluhan nyeri punggung bawah pada penelitian ini dapat di alami siapa saja, pada umur berapa saja. Namun, keluhan nyeri punggung bawah berhubungan dengan beberapa faktor etiologik tertentu yang lebih sering dijumpai pada umur yang lebih tua. Biasanya nyeri ini mulai dirasakan oleh pengrajin gerabah yang berumur 25 tahun keatas, bahkan keluhan nyeri punggung ini semakin lama semakin meningkat hingga umur lansi ( lanjut usia) sekitar 55 tahun.

Pada observasi langsung di lokasi penelitian, pengrajin yang berumur muda cara kerjanya sama dengan yang berumur tua, sehingga beban kerja yang dirasakan juga sama. Maka dalam hal ini pengrajin yang sudah berumur tua harus lebih memperhatikan kondisi fisik tubuhnya, lebih banyak beristirahat dan tidak memaksakan diri untuk bekerja. Karena kondisi fisik pengrajin yang berumur muda beda dengan pengrajin yang sudah tua, umur muda lebih kuat dan gesit dalam melakukan pekerjaanya dibandingkan dengan pengrajin berumur tua.

Penelitian ini sejalan dengan penelitian yang dilakukan (putranto, 2014), yang menunjukkan bahwa responden berumur tua ( $>35$ tahun) yang mempunyai keluhan low back pain (LBP) hasil analisis data dengan menggunakan uji chi-square menunjukkan nilai $p=0,043(a<0,05)$. Dapat diinterpretasikan bahwa ada hubungan umur dengan keluhan low back pain (LBP) pada penjahit .

Pekerja yang berusia lebih dari atau sama dengan 40 tahun akan menyebabkan faktor risiko mengalami keluhan nyeri punggung bawah. Usia lebih besar atau sama dengan 40 tahun berisiko mengalami keluhan nyeri punggung bawah seperti pendapat dari ( Tarwaka,2004) bahwa keluhan otot sekeletal mulai dirasakan pada usia kerja 25-65 tahun. Keluhan pertama biasanya dirasakan pada usia 35 tahun dan tingkat keluhan akan terus meningkat sejalan dengan bertambahnya umur. Hal ini terjadi karena pada umur setengah baya, kekuatan dan ketahanan otot mulai menurun, sehingga risiko terjadi keluhan otot meningkat. Pengrajin yang berusia lebih dari atau sama dengan 40 tahun dan kurang dari 40 tahun pada hasil penelitian dilapangan pembagian kerjanya tidak dibedakan. Sehingga dianjurkan kepada para pengrajin yang berusia lebih dari atau sama dengan 40 tahun, untuk memperhatikan kesehatan dengan menerapkan prinsip kerja secara ergonomis agar terhindar dari cedera, bila susah harus istirahat (jangan dipaksa) dan bila lapar atau haus harus makan atau minum (jangan ditahan) (Wignjosoebroto, 2003). 


\section{Lama Kerja}

Lamanya seseorang bekerja dengan baik dalam sehari sekitar 6-8 jam dan sisanya untuk beristirahat atau berkumpul dengan keluarga. Dalam seminggu orang bisa bekerja dengan baik selam 40 jam yang dapat dibagi dalam 5 atau 6 hari kerja. Lebih dari itu akan kecenderungan timbulnya hal-hal yang negatif. Makin panjang waktu kerja makin besar kemungkinan terjadinya hal-hal yang tidak diinginkan.

Distribusi responden dari 67 pengrajin gerabah yang bekerja lebih dari 8 jam sebanyak 5 orang $(7 \%)$ dan yang bekerja selama atau kurang dari 8 jam yaitu sebanyak 62 orang (93\%). Hasil tabulasi silang antara lama kerja dengan keluhan nyeri punggung bawah pada pengrajin gerabah menunjukkan bahwa responden dengan keluhan nyeri punggung bawah lebih tinggi pada pengrajin dengan lama kerja selama atau kurang dari 8 jam sebanyak 44 orang (66\%). Hasil uji statistik diperoleh pvalue $=0,666$ karena nilai $\mathrm{p}>0,05$ maka dinyatakan $\mathrm{Ho}$ diterima dan $\mathrm{Ha}$ ditolak yang berarti bahwa tidak terdapat hubungan yang signifikan antara keluhan nyeri punggung bawah dengan Lama Kerja pada pengrajin gerabah di Lingkungan Sandi. Keluhan nyeri punggung bawah tidak dipengaruhi oleh waktu kerja disebabkan karena, pada penelitian ini beberapa pengrajin gerabah memiliki waktu kerja istirahat yang seimbang.

Penelitian ini sejalan dengan penelitian yang dilakukan (Machmud,2014) yang menyatakan bahwa tidak ada hubungan antara waktu kerja dengan keluhan nyeri punggung bawah sebanyak 56 responden $(96,6 \%)$ yang menderita nyeri punggung bawah dengan lama waktu kerja perhari $<8$ jam dan 22 responden (100\%) menderita nyeri punggung bawah dengan lama waktu kerja perhari $>8$ jam. Sedangkan 2 responden $(3,4 \%)$ yang tidak menderita nyeri punggung bawah dengan lama waktu kerja perhari > 8 jam tidak ditemukan dalam penelitian ini $(0 \%)$.

Lama kerja adalah waktu yang ditentukan untuk melakukan pekerjaan. Harrinton (2011) juga mengatakan bahwa lamanya waktu kerja berlebih dapat meningkatkan human error atau kesalahan kerja karena kelelahan yang meningkat dan jam tidur yang kurang. Lama kerja berkaitan dengan keadaan fisik tubuh pekerja. Pekerjaan fisik yang berat akan mempengaruhi kerja otot. Jika pekerjaan berlangsung lama tanpa istirahat yang cukup, maka kemampuan tubuh akan menurun dan dapat menyebabkan kesakitan pada anggota tubuh (Suma'mur,2009). Sehingga bila pekerja mendapatkan istirahat yang cukup maka akan mengurangi risiko terjadinya keluhan nyeri punggung bawah.

\section{Masa Kerja}

Berdasarkan penelitian pada kategori masa kerja dari 67 responden semua (100\%) pengrajin gerabah di Lingkungan Sandi termasuk dalam pekerja lama yaitu bekerja diatas 5 tahun, dilihat pada tabel 5.10 pada penelitian ini tidak dilakukan uji chi square karena semua pengrajin gerabah di Lingkungan Sandi adalah pekerja lama jadi hasil tabulasi silang antara masa kerja dengan keluhan nyeri punggung bawah diperoleh persentase distribusi responden yang selalu mengalami keluhan nyeri punggung bawah yaitu sebanyak 48 orang $(72 \%)$. Hal ini menunjukkan bahwa masa kerja berpengaruh dengan keluhan nyeri punggung bawah yang dirasakan pengrajin karena lebih banyak responden yang selalu mengalami keluhan nyeri punggung bawah. Dilihat dari masa kerja yang sudah lama, bahkan kebanyakan dari pengrajin tersebut sudah memulai membuat gerabah dari kecil yang merupakan pekerjaan turun temurun dari keluarga mereka. Masa kerja yang lama bisa memberikan keluhan nyeri punggung disebabkan penyakit nyeri punggung bawah merupakan penyakit yang membutuhkan waktu lama untuk berkembang dan bermanifestasi.

Dari hasil wawancara langsung dengan responden, kebanyakan dari mereka $(68,7 \%)$ sudah membuat kerajinan gerabah sejak umur 10 tahun sampai sekarang, ada yang terhitung sudah bekerja selama kurang lebih 40 tahun. Hal ini tentu dapat berpengaruh pada keluhan nyeri punggung bawah yang dirasakan respoden. Masa kerja yang merupakan salah satu faktor risiko terjadinya nyeri punggung bawah memang memiliki hubungan yang signifikan terhadap kejadian nyeri punggung bawah, masa kerja dengan sikap kerja duduk lebih dari 5 tahun mempunyai resiko lebih tinggi terpapar nyeri punggung bawah dibandingkan dengan responden yang masa kerjanya kurang dari sama dengan 5 tahun, hal ini dikarenakan pembebanan tulang belakang dalam waktu lama mengakibatkan rongga diskus menyempit secara permanen dan juga mengakibatkan degenerasi tulang belakang yang akan menyebabkan nyeri punggung bawah (Pratiwi, 2009). 
Penelitian ini sejalan dengan penelitian yang dilakukan (Putranto 2014), yang menyatakan bahwa ada hubungan antara masa kerja dengan keluhan nyeri punggung hasil analisis data dengan menggunakan uji Chi-Square menunjukkan nilai $p=0,033 \quad(p<0,05)$. Dapat diinterpretasikan bahwa ada hubungan antara kategori masa kerja dengan keluhan low back pain (LBP) pada penjahit dikawasan pasar sentral Kota Makassar.

Menurut teori yang dikemukakan Hasyim dalam Tarwaka (2015) bahwa masa kerja menyebabkan beban statis yang terus menerus, apabila pekerja tidak memperhatikan faktor - faktor ergonomi, maka akan lebih mudah menimbulkan keluhan nyeri punggung bawah. Semakin lama bekerja, semakin tinggi tingkat resiko untuk menderita nyeri punggung bawah, terutama dengan posisi statis, yang akan mengakibatkan regangan otot - otot, fasia, dan ligamentum disepanjang daerah torakal.

\section{Sikap Kerja}

Berdasarkan hasil observasi penelitian pada kategori sikap kerja dari 67 responden $(100 \%)$ yang pada saat bekerja dengan posisi duduk tegak diperoleh hasil 0 $\%$, posisi membungkuk berlebihan pada saat bekerja diperoleh hasil $67 \%$, tidak merubah posisi membungkuk ke posisi duduk tegak saat bekerja selalu (52\%) dan jarang (15\%), saat bekerja melakukan posisi duduk yang lama diperoleh hasil $67 \%$. Dilihat dari tabel 5.11 pada penelitian ini tidak dilakukan uji chi square karena semua pengrajin gerabah di Lingkungan Sandi bekerja dengan posisi kerja yang sama dan angka pada kuesioner juga sama, distribusi responden yang selalu mengalami keluhan nyeri punggung bawah yaitu sebanyak 48 orang $(72 \%)$. Hal ini menunjukkan bahwa sikap kerja berpengaruh dengan keluhan nyeri punggung bawah karena lebih banyak responden yang selalu mengalami keluhan nyeri punggung bawah. Adanya pengaruh sikap kerja dengan nyeri punggung bawah pada pengrajin gerabah di lingkungan sandi di pengaruhi oleh posisi duduk yang tidak ergonomi. Posisi tubuh dalam bekerja sangat bergantung oleh jenis pekerjaan yang dilakukan, setiap posisi kerja memiliki pengaruh yang berbeda terhadap tubuh.

Penelitian ini sejalan dengan penelitian yang dilakukan (Putri Sirajud, 2017), yang menyatakan ada hubungan antar sikap kerja dengan keluhan nyeri punggung bawah pada pekerja bagian pecker di PT Bogatama Marinusa (Bomar). Hasil uji statistik dengan menggunakan chi-square diperoleh nilai $p=0,000$ karena nilai probabilitas $a<0,05$ maka Ho ditolak yang berarti ada pengaruh hubungan antara sikap tubuh terhadap keluhan nyeri punggung bawah pada packer di PT.BOMAR Makassar. Pengrajin gerabah di Lingkungan Sandi pada saat membuat kerajinan gerabah selalu bekerja posisi kerja yang tidak ergonomi yaitu dengan duduk dengan posisi kaki tertekuk, badan membungkuk, dan leher yang menunduk dalam waktu kerja selama berjam-jam, sehingga dengan posisi kerja tersebut dapat meyebabkan keluhan nyeri punggung bawah. Pengrajin gerabah membuat gerabah secara manual dan dengan alat seadanya sehingga mereka tetap bekerja dengan posisi yang tidak ergonomi, dan ketidaktahuan mereka bahwa posisi kerja yang tidak baik dapat menyebabkan penyakit kerja karena kebanyakan warga pengrajin tersebut hanya bersekolah sampai dengan tingkat sekolah dasar dan lebih memilih bekerja membuat kerajinan gerabah.

Mengerjakan pekerjaan dengan sikap kerja duduk yang terlalu lama dan sikap kerja yang salah dapat mengakibatkan otot rangka (skeletal) termasuk tulang belakang sering merasakan nyeri dan cepat lelah. Nyeri punggung merupakan salah satu masalah yang dihadapi oleh pengerajin akibat posisi duduk saat bekerja. Menurut Tri Heriyanto, dalam Gempur (2013), menjelaskan bahwa nyeri punggung bawah (pinggang) merupakan salah satu penyakit akibat posisi duduk yang tidak ergonomis. Nyeri punggung bawah (pinggang) adalah perasaan nyeri di daerah lubosakral dan sakroiliakal. Penyebab nyeri pinggang (back pain) yang paling sering adalah duduk terlalu lama, sikap duduk yang salah, aktifitas yang berlebihan. Menurut Safitri dII (2010) "otot-otot punggung biasanya mulai letih setelah duduk 15-20 menit".

Posisi kerja yang tidak benar dan dipaksakan dapat menimbulkan kelelahan pada otot sehingga kerja menjadi tidak efisien. Dalam jangka waktu yang lama dapat menyebabkan gangguan fisik dengan keluhan yang dirasakan pada punggung (Nurmianto, 1996). Posisi tubuh fleksi, ekstensi dan rotasi punggung pada saat berkerja akan menyebabkan otot pada perut akan menjadi lemah sehingga dapat menyebabkan lordosis yang belebihan. Secara anatomis lordosis yang berlebihan pada lumbal akan mengakibatkan penyempitan saluran atau menekan saraf tulang belakang dan penonjolan kebelakang dari ruas tulang rawan (diskus invertebralis). Hal inilah yang 
Jurnal Sulolipu : Media Komunikasi Sivitas Akademika dan Masyarakat

Vol. 19 No.12019

e-issn : 2622-6960, p-issn : 0854-624X

kemudian menyebabkan nyeri punggung bawah (Tarwaka, 2004).

Posisi duduk yang ergonomi yaitu posisi horizontal sejajar dengan lantai, posisi telapak kaki menapak ke tanah bila tidak berarti posisi duduk anda terlalu tinggi, bantalan kursi menopang punggung bagian bawah sehingga punggung tetap tegak, merubah posisi duduk secara berkala selama bekerja karena duduk dalam posisi yang tetap dalam jangka waktu lama bisa menyebabkan ketidaknyamanan, punggung santai tapi tidak membungkuk, kepala tak membungkuk atau terlalu condong ke depan.

\section{PENUTUP}

\section{KESIMPULAN}

Kesimpulan dari penelitian ini adalah dari empat variabel yang diteliti tiga yang mempunyai hubungan dengan keluhan nyeri punggung bawah yaitu umur, masa kerja, sikap kerja dan satu variabel yang tidak memiliki hubungan yaitu lama kerja.

\section{SARAN}

1. Diharapkan kepada pengrajin gerabah agar memperbaiki teknik cara bekerja memperhatikan kesehatan dengan menerapkan prinsip kerja secara ergonomis agar terhindar dari cedera, dan penyakit akibat kerja lainnya.

2. Pengrajin hendaknya memperhatikan posisi duduknya ketika bekerja dan melakukan rileksasi ketika ada waktu senggang dalam bekerja agar otototot punggung tidak mengalami kekakuan.

3. Bagi peneliti selanjutnya agar meneliti faktor-faktor lain yang belum dijadikan variabel dalam penelitian ini yang mempengaruhi keluhan nyeri punggung bawah.

\section{DAFTAR PUSTAKA}

Adzim. 2013. Penyakit Akibat Kerja, from Sistem Manajemen Keselamatan Kerja. (online) http://sistemmanajemenkeselamatankerja.blogspot.com. Diakses 7 desember 2017

Ahmad Affan. 2014. Hubungan Posisi Duduk Dengan Nyeri Punggung Bawah Pada Penjahit Vermak Levis Di Pasar Tanah Pasir Kelurahan Penjaringan Jakarta Utara. Skripsi. Universitas Esa Unggul. Jakarta. (Online) http://download.portalgaruda.org. Diakses pada tanggal 07 Desember 2017

Anies. 2005. Penyakit Akibat Kerja. Jakarta: PT Elex Media Komputindo.

Bimaariotejo. 2009. Nyeri Pinggang Bawah. (online) http://bimaariotejo.wordpress.com/ (diakses pada tanggal 08 Desember 2017

Defriyan. 2011. Faktor-Faktor Yang Berhubungan Dengan Keluhan Nyeri Punggung Bawah Pada Proses Penyulaman Kain Tapis Di Sanggar Family Art Bandar Lampung. Universitas Islam Negeri Syarif Hidayatullah Jakarta. (online) http://repository.uinjkt.ac.id (diakses pada tanggal 15 Mei 2018).

Fuady Ahmad Rifqi. 2013. Faktor-Faktor Yang Berhubungan Dengan Musculoskeletal Disorders (MSDs) Pada Pengrajin Sepatu Di Perkampungan Industri Kecil (PIK) Penggilingan Kecamatan Cakung. Skripsi.Fakultas Kedokteran Dan IImu Kesehatan Universitas Islam Negeri. Makassar. (Online) http://repository.uinjkt.ac.id._Diakses pada tanggal 07 Desember 2017.

Gempur. Santoso. 2013. Kursi Ergonomis Untuk Menurunkan Kelelahan Tenaga Kerja SPBU Berdasarkan Fluktuasi Asam Laktat dan Glukosa Dalam Darah. Fakultas Teknologi Industri Universitas PGRI Adi Buana Surabaua. (online): http://www.gempursantoso.com/. Diakses pada tanggal 07 Desember 2017.

Giring Novrianto. 2016. Hubungan Teknik Mengangkat Beban Dengan Keluhan Nyeri Punggung Bawah Pada Pekerja Angkut Beras Di Pasar Makale Tahun 2015. Makassar: Fakultas Kesehatan Masyarakat Universitas Hasanuddin. (Skripsi tidak dipublikasikan). 
Jurnal Sulolipu : Media Komunikasi Sivitas Akademika dan Masyarakat

Vol. 19 No.12019

e-issn : 2622-6960, p-issn : 0854-624X

Halimah. (2012). Karateristik Penderita Nyeri Punggung Bawah (NPB) yang Rawat Inap di Rumah Sakit Umum Dr. Pirngadi Medan Tahun 2009-2010. Repository USU , 30. (Online) http://repository.usu.ac.id. Diakses 8 Desember 2017.

Harrington. Gill. 2005. Buku Saku Kesehatan Kerja. Jakarta: Buku Kedokteran EGC.

Hoy, D, Brain, Williams, dan March. 2012. A Syastematic Review Of The Global Prevalence Of Low Back Pain. (Online) http://onlinelibrary.wiley.com. Diakses 7 Desember 2017.

ILO. 2013. Safety And Health at Work. (Online) http://www.ilo.org/[pdf]. Diakses 8 Desember 2017.

Koesyanto, H. 2013. Masa Kerja dan Sikap Kerja terhadap Nyeri Punggung. Jurnal Kesehatan Masyarakat. 9(1). (Online) http://www.neliti.com. Diakses 8 desember 2017

Kurniawidjaja, Meily L. 2012. Teori dan Aplikasi Kesehatan Kerja. Jakarta: Universitas Indonesia. Cetakan Ketiga.

Kuswana, Sunaryo Wowo. 2017. Ergonomi dan K3 Kesehatan Keselamatan Kerja. Bandung: PT Remaja Rosdakarya. Cetakan Ketiga.

Lawry, George. 2011. Pemeriksaan Muskuloskeletal yang Sistematis. Jakarta: Erlangga.

Lebang, Erikar. 2015. Yoga Atasi Backpain. Jakarta: Pustaka Bunda. (online) https://books.google.co.id/. Diakses 8 Desember 2017.

Machmud, I. (2014) Faktor-faktor yang Berhubungan dengan kejadian Nyeri Punggung Bawah pada Tenaga Kerja Bongkar Muat (TKBM) di Pelabuhan Belawan Medan.Repository USU,10. (Online) http://media.neliti.com. Diakses 8 Desember 2017.

Nurliah. Aah. 2012. Analisis Risiko Musculoskeletal Disordes (MSDs) Pada Operator Forklift Di PT.LLI Tahun 2012. Fakultas Kesehatan Masyarakat, Universitas Indonesia (online): http://lib.ui.ac.id (diakses pada tanggal 15 Mei 2018).

Nurmianto, Eko. 1996. Ergonomi: Konsep Dasar dan Aplikasinya. Surabaya: Guna Widya.

Nurmianto. Eko. 2008. Ergonomi: Konsep Dasar Dan Aplikasinya. Gunawidya: Surabaya. Edisi Kedua.

Nurzannah. (2015). Hubungan Faktor Resiko dengan Terjadinya Nyeri Punggung Bawah (Low Back Pain) Pada Tenaga Kerja Bongkar Muat (TKBM) di Pelabuhan Belawan Medan. Repository USU , 10.

Perdani. Putri. 2010. Pengaruh Postur dan Posisi Tubuh Terhadap Timbulnya Nyeri Punggung Bawah. Fakultas Kedokteran:Universitas Deponegoro. (Online): http://eprints.undip.ac.id. Diakses 10 Desember 2017.

Pratiwi, dkk. 2009. Beberapa Faktor Yang Berpengaruh Terhadap Keluhan Nyeri Punggung Bawah Pada Penjual Jamu Gendong. Jurnal promosi kesehatan indonesia. 4(1). (Online) http://media.neliti.com. Diakses pada tanggal 07 Desember 2017.

Putranto, H.T. 2014. Hubungan Postur Tubuh Menjahit Dengan Keluhan Low Back Pain pada Penjahit Di Pasar Sentral Kota Makassar. Jurusan Keselamatan dan Kesehatan Kerja. http://repository.unhas.ac.id (diakses pada tanggal 15 Mei 2018).

Rista, I. (2010). Hubungan Mengangkat Beban dan Frekuensi Angkat Dengan Keluhan Nyeri Punggung Pada Pekerja Pengangkut Buah di Pasar Johar Semarang. Unnes. (Online) http://lib.unnes.ac.id. Diakses pada tanggal 07 Desember 2017.

Ruslan. 2012. Nyeri Punggung Bawah, from Mediacastore. (online) http://mediacastore.com/. Diakses 7 Desember 2017. 
Jurnal Sulolipu : Media Komunikasi Sivitas Akademika dan Masyarakat

Vol. 19 No.12019

e-issn : 2622-6960, p-issn : 0854-624X

Santisa Adhiyoga, Widyadharma Eka, Purwata Eko, 2016. Korelasi Lama Duduk Dengan Keluhan Nyeri Punggung Bawah Pada Pekerja Hotel The Grand Santhi Denpasar, Jurnal Ilmu Kedokteran, 5 (10). (Online) http://ojs.usnud.ac.id. Diakses pada tanggal 07 Desember 2017.

Santoso, Gempur. 2004. Manajemen Keselamatan \& Kesehatan Kerja. Jakarta: Prestasi Pustaka Publisher.

Sarnad. (2010). Prevalence of Low Back Pain and it Risk Factor Among

School Teachers. American Journal of Applien Sciences, 50.

Sianturi Mei, Widyadharma, Purwata Eko, 2015, Faktor-Faktor Yang Berhubungan Dengan Keluhan Low Back Pain (Nyeri Punggung Bawah) Pada Supir Angkot Rahayu Medan Ceria 103 Di Kota Medan, Jurnal IImu Kedokteran, 5 (10). (Online) http://jurnal.usu.ac.id. Diakses 7 Desember 2017.

Samara, D. 2011. Duduk statis sebagai faktor risiko terjadinya nyeri punggung bawah pada pekerja perempuan. (online) http://www.univmed.org diakses tanggal 15 Mei 2018

Sirajud Putri. 2017. Faktor Yang Berhubungan Dengan Keluhan Nyeri Punggung Bawah Pada Pekerja Bagian Packer Di PT. Bogatama Marinusa (BOMAR) Kota Makasar, Makassar: Fakultas Kesehatan Masyarakat Universitas Muslim Indonesia. (Skripsi tidak dipublikasikan).

Soewarno, A. 2005. Perbaikan Lingkungan Kerja pada Pengrajin Ukiran Kelongsong Peluru dengan Menyesuaikan Tinggi Meja Kerja di Desa Kamasan, Kalungkung. Jurnal Natah. (Online) http://ojs.unud.ac.id/.pdf. Diakses 7 Desember 2017.

Suma'mur, P.K, 2009. Higiene Perusahaan dan Kesehatan Kerja (Hiperkes). CV. Sagung Seto, Jakarta.

Suma'mur. 2013. Higiene Perusahaan dan Kesehatan Kerja (Hiperkes). CV. Sagung Seto: Jakarta. Edisi kedua.

Susetyo Joko, Isna Titin, dan Hastiko Suyasning. 2008. Prevalensi Keluhan Subyektif Atau Kelelahan Karena Sikap Kerja Yang Tidak Ergonomis Pada Pengrajin Perak. Jurnal Teknologi. 1(2): 141-149. (Online) http://jurtek.akprind.ac.id/.pdf. Diakses 7 Desember 2017.

Tarwaka, dkk. 2004. Ergonomi Untuk Keselamatan, Kesehatan Kerja, Dan Produktivitas. Surakarta: UNIBA Press.

Tarwaka. (2015). Keselamatan, Kesehatan Kerja dan Ergonomi (K3E) dalam Perspektif Bisnis. Surakarta: Harapan Press Surakarta.

Tatilu, J.. E. (2014). Hubungan antara Sikap Kerja dengan Keluhan Nyeri Punggung Bawah Pada Tenaga Kerja Bongkar Muat di Kantor Kesyahbandaraan dan Otoritas Pelabuhan Manado. FKM UNSRAT , 10 (online): http://fkm.unsrat.ac.id. Diakses 7 Desember 2017. 